ORIGINAL ARTICLE

\title{
Do team gymnasts compete in spite of symptoms from an injury?
}

\author{
M L Harringe, S Lindblad, S Werner
}

Br J Sports Med 2004;38:398-401. doi: 10.1136/bjsm.2002.001990

See end of article for authors' affiliations

......................

Correspondence to: Marita L Harringe,

Karolinska Institutet Department of Surgical Sciences, Sports Medicine Section, Stockholm 171

76, Sweden; marita. harringe@kirurgi.ki.se

Accepted 8 July 2003

\begin{abstract}
Background: Gymnasts practise many hours a week, and symptoms from injuries do not seem to stop them from continuing with practice. They may even compete with symptoms from injuries, which could increase the risk of reinjury, or of the occurrence of a more severe injury.

Objectives: To investigate whether team gymnasts compete at high level in spite of symptoms from an injury.

Methods: 188 male and female competitors participating in the Swedish Cup for juniors and seniors answered a questionnaire about symptoms from injuries on the day of the competition.

Results: More than half the gymnasts $(58 \%)$ competed despite having symptoms from an injury on the day of the competition. More seniors than juniors competed in spite of symptoms from an injury $(p=0.006)$. Two of three team gymnasts (65\%) reported symptoms from the lower extremities and around one in five $(22 \%)$ reported back symptoms. Fifty five per cent of the gymnasts reported recurrence of an injury at the same site (reinjury).

Conclusions: There was a high prevalence of symptoms from injuries on the day of competition. This did not stop the team gymnasts from competing.
\end{abstract}

G ymnasts and ballet dancers tend to resume practising without being fully rehabilitated, ${ }^{12}$ or even more remarkably, continue to practise despite symptoms from injuries. ${ }^{3-5}$ Caine et al reported that artistic gymnasts practise with symptoms from injuries $71 \%$ of the time. Artistic gymnastics is the most common form of gymnastics. Injuries and risk factors in this sport have been studied during the last two decades. Team gymnastics, on the other hand, is a fairly recent sport, originating in Scandinavia, with the first European championships (Euroteam) taking place in 1996, and it has not been studied closely. Sixteen countries participated in the Euroteam 2000 competition and the sport is rapidly spreading throughout the world. A team at the highest level of competition consists of six to 12 participants, and the competition comprises three events: tumbling, trampette (vaulting), and a floor programme (Euroteam regulations, 1998). Tumbling and trampette are explosive events where the teams perform three series of tumbling runs and three series of vaults. At least six of the gymnasts have to participate at the same time in each series in these events. The floor programme is a more aerobic event, comparable to team rhythmic gymnastics, and the judges are looking for a perfectly synchronised team. In comparison with artistic gymnasts, team gymnasts at the highest level of competition spend less time in the gymnasium, are older, and specialise in tumbling and vaulting. ${ }^{\circ}$

Bak et al studied Danish gymnasts and found a higher injury rate per 100 participants over one season in team gymnasts than in artistic gymnasts. ${ }^{6}$ This was primarily explained by a larger proportion of overuse injuries in team gymnasts, probably resulting from repetitive microtrauma owing to their longer experience as gymnasts. ${ }^{6}$ This could mean that the gymnasts have symptoms from their injuries during competition as well as during practice. During competition the demands on the performer are particularly high and symptoms from even a minor injury could increase the risk of a new injury or a reinjury. Our aim in this study was therefore to investigate whether team gymnasts compete in spite of symptoms from an injury.

\section{METHODS}

We asked 298 team gymnasts participating in the Swedish Cup for juniors (aged 12-18, $\mathrm{n}=113$ ) and seniors $(\geqslant 14$ years, $\mathrm{n}=185$ ) to answer a questionnaire about symptoms from injuries on the day of the competition. The Swedish Cup represents the highest level of team gymnastics for juniors and seniors in Sweden. Three times as many female as male competitors participated in these competitions. The questionnaires were handed out consecutively to the team gymnasts as they arrived at the gymnasium. They were asked to return the questionnaires at the end of the competitions. Sixty three per cent of the questionnaires $(n=188)$ were answered. The dropout rate was not correlated with sex or age. Background and training data are presented in table 1 .

\section{The questionnaire}

The questionnaire was divided into two parts. The first part consisted of descriptive questions on age, body weight, height, gymnastics experience (years), training sessions per week, training hours per week, and how much time they spent on warming up, stretching, strength training, and the three events of tumbling, trampette, and floor programme. The gymnasts were given defined time periods for each of the questions about training and were instructed to mark the period corresponding to their training routine. Body mass index (BMI) was calculated as weight/height ${ }^{2}$. A test-retest of the first part of the questionnaire was done using Spearman's $R$ and showed a correlation of between 0.92 and 1.0 for all questions except strength training, where the correlation was 0.72 .

The second part of the questionnaire consisted of questions about symptoms from injuries on the day of the competition, irrespective of severity. The team gymnasts were given a list of body locations comprising face, teeth, shoulder, rib, neck, back, arm, wrist/hand, hip/trunk, knee, ankle/foot, and "other part of the body", and they were asked to mark the site of the injury. For the item "other part of the body", they were asked to describe the site where they had symptoms. 
Table 1 Background and training data for team gymnasts in the Swedish Cup $(n=188)$

\begin{tabular}{|c|c|c|c|c|}
\hline & \multicolumn{2}{|c|}{ Junior team gymnasts } & \multicolumn{2}{|c|}{ Senior team gymnasts } \\
\hline & Female $(n=60)$ & Male $(n=21)$ & Female $(n=78)$ & Male $(n=29)$ \\
\hline Age (years) & $15.4(1.2)$ & $14.5(1.1)$ & $18.9(2.8)$ & $21.2(2.9)$ \\
\hline Height $(\mathrm{cm})$ & $162.4(6.7)$ & $166.6(10.4)$ & $161.5(5.0)$ & $176.8(4.6)$ \\
\hline Weight $(\mathrm{kg})$ & $51.6(6.5)$ & $55.0(11.5)$ & $52.9(5.9)$ & $70.1(6.6)$ \\
\hline Body mass index $\left(\mathrm{kg} / \mathrm{m}^{2}\right)$ & $19.5(1.6)$ & $19.8(1.9)$ & $20.3(1.7)$ & $22.4(1.4)$ \\
\hline Gymnastics experience (years)* & 7 to $9(1$ to 15$)$ & 7 to $9(1$ to 12$)$ & 10 to $12(7$ to 15$)$ & 13 to $15(4$ to 15$)$ \\
\hline Training sessions/week & $3.7(0.7)$ & $3.6(0.9)$ & $3.5(0.6)$ & $3.5(0.6)$ \\
\hline Training hours/week* & 7 to $9(1$ to 15$)$ & 7 to $9(1$ to 15$)$ & 7 to $9(4$ to 15$)$ & 7 to 9 (4 to 12$)$ \\
\hline Tumbling sessions/week & $2.7(0.8)$ & $3.0(0.8)$ & $2.7(0.9)$ & $2.2(0.8)$ \\
\hline Trampette sessions/week & $2.7(0.9)$ & $3.0(0.9)$ & $2.7(0.8)$ & $2.4(0.9)$ \\
\hline Floor programme sessions/week & $1.9(1.0)$ & $2.1(1.1)$ & $2.3(1.0)$ & $1.6(0.8)$ \\
\hline Strength training sessions/week & $2.9(1.1)$ & $2.7(1.1)$ & $2.2(1.3)$ & $2.7(1.2)$ \\
\hline Warming up $(\mathrm{min})^{*}$ & $20(5$ to 20$)$ & $15(5$ to 20$)$ & $15(5$ to 20$)$ & $15(10$ to 20$)$ \\
\hline Stretch $(\min )^{*}$ & $10(5$ to 15$)$ & $10(5$ to 15$)$ & $10(5$ to 15$)$ & $10(5$ to 15$)$ \\
\hline
\end{tabular}

The subjects were asked when the injury occurred and in what event. They were also asked whether the skill they were practising when they were injured was new to them or if they had been practising it for one year, two years, or more. Finally the gymnasts reported whether they had suffered an injury at the same site previously (reinjury) during their career as gymnasts. A test-retest of the second part of the questionnaire was carried out and showed $100 \%$ correlation for all questions except for the event when the injury occurred (92\%), how long they had been practising the skill (92\%), and the reinjury rate $(83 \%)$.

\section{Statistics}

Quantitative data are presented as medians (range) and means (SD). Categorical data are presented by cross tables and proportions/percentages. Statistical analyses of the dependent variables-the day of the competition and reinjury-were done using logistic regression modelling. Results are presented based on a multivariate model. Odds ratios and corresponding 95\% confidence intervals (CI) are presented. Statistical significance was set at the $5 \%$ level $(\mathrm{p}<0.05)$.

\section{RESULTS}

In all, $58 \%$ of the team gymnasts $(n=110)$ reported symptoms from 147 injuries on the day of competition (fig 1). The most common sites for symptoms were ankle/foot $(n=37)$, back $(n=32)$, and knee $(n=30) ; 65 \%(n=95)$ of

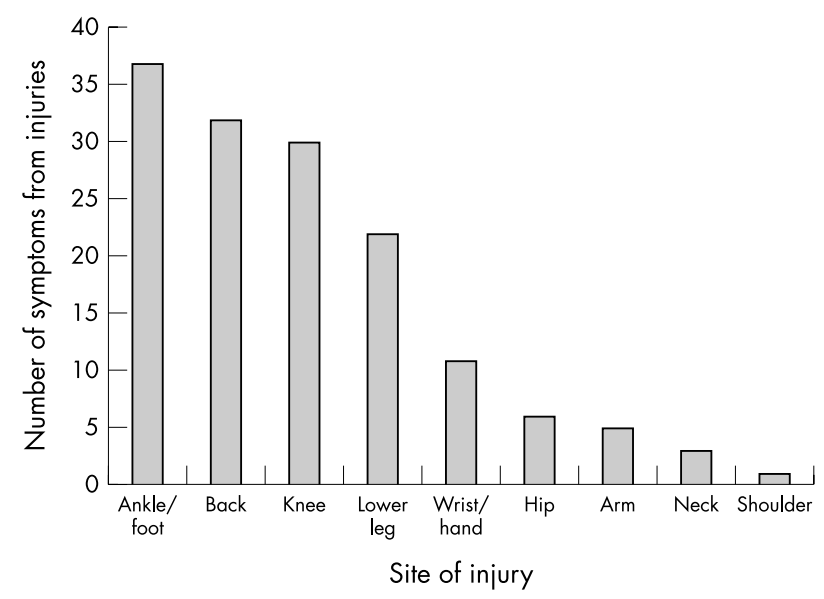

Figure 1 Site of injury and symptoms from injuries at the Swedish Cup in team gymnastics for juniors and seniors $(n=188)$. A team gymnast may have symptoms from more than one injury. the reported symptoms came from the lower extremities and $22 \%(\mathrm{n}=32)$ from the back (fig 1$)$.

Of the injuries giving rise to symptoms, $81 \%$ were sustained during practice, $12 \%$ during competition, 3\% during exhibitions, and $4 \%$ outside gymnastics. Tumbling accounted for $35 \%$ of the injuries, while $23 \%$ were sustained in trampette, $11 \%$ in springboard training, $9 \%$ in the floor programme, and $22 \%$ at other occasions. Forty five per cent of the injuries occurred in a skill that the gymnasts had practised for two years or more, $12 \%$ in a skill they had practised for at least one year, 10\% in a new skill, and in 33\% of the cases they could not recall how long they had practised the skill.

\section{Sex and age differences}

A significantly larger number of seniors than juniors competed while they had symptoms from an injury $(p=0.006$, table 2$)$. Comparing locations between male and female competitors and juniors and seniors, male senior gymnasts reported more ankle/foot, back and wrist/hand problems, while female gymnasts reported more knee and lower leg problems (fig 2). The male junior gymnasts did not report any back symptoms.

\section{Recurrent injuries}

Fifty five per cent $(n=103)$ of the 188 gymnasts reported that they had suffered a reinjury during their career as gymnasts (fig 3). In all, 137 reinjuries were reported. Fifty five per cent $(n=75)$ of those 137 reinjuries involved the lower extremity, while back problems accounted for $31 \%$ $(\mathrm{n}=42)$.

\section{Potential risk factors for injuries in team gymnastics} Team gymnasts who never stretched reported a larger number of injuries to the ankle/foot $(p=0.01$, table 2$)$. The estimated risk for an injury to the back increased by 2.11 times $(p=0.06$, table 2 ) for each additional training session per week that the gymnast spent on tumbling. By contrast, a trend in the opposite direction was found for trampette training - that is, the risk of injury to the back was reduced with each additional trampette training session per week $(\mathrm{p}=0.15$, table 2$)$. Gymnasts who reported more reinjuries to the knees had a significantly higher BMI than those with no knee reinjuries $(\mathrm{p}=0.049$, table 2$)$.

\section{DISCUSSION}

Our aim in this study was to investigate whether team gymnasts compete in spite of symptoms from an injury. Fifty eight per cent of the gymnasts reported that they competed despite injury symptoms. Most of the injury symptoms were 
Table 2 Symptoms from injuries and reinjuries reported by gymnasts at the Swedish Cup in team gymnastics for juniors and seniors, using multivariate logistic regression analyses $(n=188)$

\begin{tabular}{|c|c|c|c|c|c|c|}
\hline \multirow[b]{2}{*}{ Site of injury } & \multicolumn{3}{|c|}{$\begin{array}{l}\text { Symptoms from an injury on the day of } \\
\text { competition }\end{array}$} & \multicolumn{3}{|l|}{ Reinjuries } \\
\hline & OR (female) & OR (male) & p Value & OR (female) & OR (male) & $\mathrm{p}$ Value \\
\hline \multicolumn{7}{|l|}{ Any site } \\
\hline Group juniors & 0.71 & 0.26 & & 0.67 & 0.15 & \\
\hline Seniors & 1.00 & 3.00 & $0.04^{*}$ & 1.00 & 1.39 & $\mathrm{NS}^{*}$ \\
\hline \multirow[t]{2}{*}{ Interaction } & & & 0.006 & & & 0.018 \\
\hline & OR & $95 \% \mathrm{Cl}$ & $\mathrm{p}$ Value & OR & $95 \% \mathrm{Cl}$ & p Value \\
\hline \\
\hline Group* & & & & 0.37 & 0.19 to 0.70 & 0.003 \\
\hline \multicolumn{7}{|l|}{ Ankle/foot } \\
\hline Group* & 0.55 & 0.25 to 1.22 & 0.14 & 0.34 & 0.15 to 0.80 & 0.01 \\
\hline Stretch-never & 9.73 & 1.34 to 57.45 & 0.01 & 5.07 & 0.91 to 28.41 & 0.06 \\
\hline \multicolumn{7}{|l|}{ Knee } \\
\hline Age (continuous) & & & & 0.91 & 0.77 to 1.08 & 0.28 \\
\hline Sex (female compared to male) & & & & 0.69 & 0.23 to 2.01 & 0.49 \\
\hline BMI & & & & 1.32 & 1.00 to 1.75 & 0.049 \\
\hline \multicolumn{7}{|l|}{ Back } \\
\hline Age (continuous) & & & & 1.13 & 1.02 to 1.25 & 0.02 \\
\hline Group* & 0.43 & 0.18 to 1.01 & 0.051 & & & \\
\hline Tumbling sessions/week & 2.11 & 0.96 to 4.68 & 0.063 & & & \\
\hline Trampette sessions/week & 0.57 & 0.27 to 1.24 & 0.15 & & & \\
\hline
\end{tabular}

located in the ankle/foot, the back, or the knee, with $65 \%$ in the lower extremities and $22 \%$ in the back. The three events in team gymnastics are all characterised by high impact to the lower extremities, which explains why injuries occur particularly at these locations. Lack of standardised surfaces, including mats and floors, and the infrequent use of shoes during practice and competition may also contribute to the production of lower extremity injuries in team gymnastics. ${ }^{7}$ Back problems were responsible for $22 \%$ of the symptoms that were present on the day of competition. This is similar to, or somewhat higher than, epidemiological reports in artistic gymnastics, ${ }^{358}$ but lower than in several other sports. ${ }^{9} 10$

Significantly more seniors than juniors competed while suffering from injury symptoms. Male senior team gymnasts reported more ankle/foot, back, and wrist/hand problems

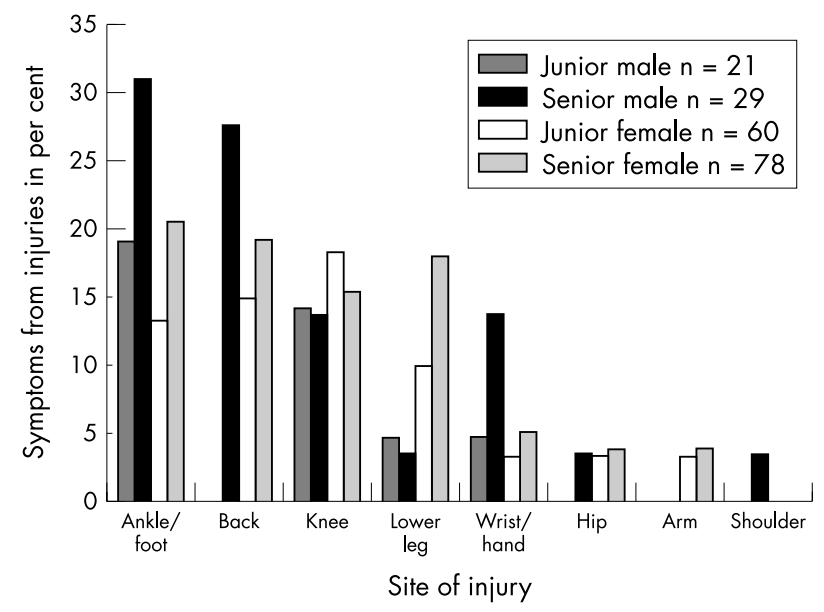

Figure 2 Symptoms from injuries on the day of competition for each category (junior male and female team gymnasts and senior male and female team gymnasts), expressed as percentages $(n=188)$. than the male junior and female team gymnasts (fig 2). The male senior team gymnasts are taller and heavier (table 1), and perform more difficult skills. This would imply greater stress to specific joints such as the ankles, spine, and wrists in male senior team gymnasts. The high impact could result in disc injuries, and early disc degeneration has been found to be a cause of back pain in male senior artistic gymnasts. ${ }^{11}$ Female team gymnasts reported more problems from the knees and lower legs. These problems could be a result of changing surfaces while preparing for competition. It is common to practise on a soft surface in order to try to reduce the risk of injury. Competitions on the other hand are carried out on hard surfaces. Team gymnasts therefore change surface from soft to hard well in advance of competition. This practice is of course common to both male and female team gymnasts, but female gymnasts may perhaps need a longer preparation time than male gymnasts. Fridén et al

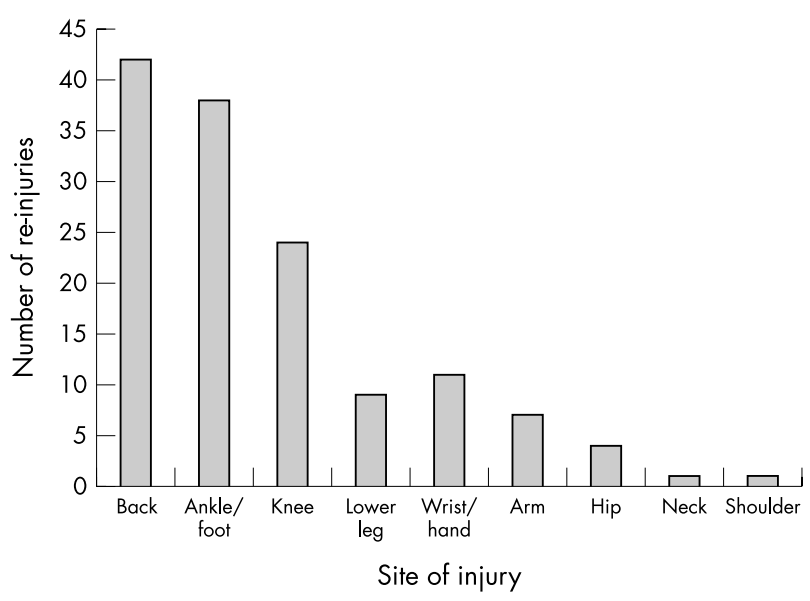

Figure 3 Number of reinjuries reported by participants in the Swedish Cup in team gymnastics for juniors and seniors $(n=188)$. 


\section{Take home message}

Team gymnasts compete in spite of symptoms from an injury. It is also common to sustain reinjury. To reduce the number of reinjuries, gymnasts who have sustained an injury should be discouraged from resuming practice and competition until adequate recovery and rehabilitation have taken place.

showed that there is a change in postural control during the different menstrual phases. ${ }^{12}$ This might influence the time needed for adaptation to a new surface. Other explanations could be malalignment of the lower extremity, or muscle fatigue owing to weak musculature in the lower extremities.

Most injuries in the present study were sustained during tumbling. An interesting observation was that team gymnasts with more trampette training in their schedule reported fewer back problems. It is possible that gymnasts practising more trampette spend less time practising tumbling. On the other hand, walking on a trampoline has been shown to activate the stabilising muscles of the lumbar spine. ${ }^{13}$ Trampette training may activate these muscles as well and thus be helpful in preventing back injuries.

Most of the injuries had occurred during practice and mainly while practising or performing skills that the gymnasts had known or practised for a long time. Lindner and Caine $^{14}$ found that injuries in artistic gymnastics occurred more often when the gymnast had been on an apparatus for a long time, and often in skills that the gymnast already knew well. They suggested that loss of concentration owing to their familiarity with the skill might be a cause of injury. Other explanations could be muscle fatigue and decreased neuromuscular coordination at the end of the practice session, as suggested by Bak et al. ${ }^{6}$

Fifty five per cent of the gymnasts reported recurrence of an injury to the same site. It is therefore likely that they return to practice and competition before being fully rehabilitated. Teams usually do not have alternative gymnasts who are as skilled as the first team members and therefore there is peer pressure for the injured gymnast to return to competition before they are fully recovered. Cain $e t$ al emphasised the importance of full recovery before returning to practice and competition in artistic gymnastics, mainly because of the risk of a reinjury or a new injury. ${ }^{1}$

A weakness of this study was the somewhat limited response rate. The questionnaire was answered by only $63 \%$ of the gymnasts. The reason for this might be that the study was carried out during a competition, when the gymnasts have their minds focused on performance. If the questions had been asked retrospectively we might have obtained a larger number of answers but they would probably not have been so accurate. The test-retest of the questionnaire showed a somewhat lower reliability for questions of a retrospective type. However, there was no correlation between dropping out and the sex or age of the participants.

Our study showed that it is common to continue to compete in spite of symptoms from injuries. This is an interesting issue which has not been much discussed. It generates several further questions. How severe are the symptoms? How many of these gymnasts are able to continue with gymnastics after the competition? How many sustain yet another injury during competition? Is there a risk of new injury or reinjury? In order to establish injury preventive programmes these are the questions that need to be answered. It is also important to identify the types of injury and the injury mechanisms in team gymnastics.

\section{Authors' affiliations}

M L Harringe, S Werner, Department of Surgical Sciences, Sports

Medicine Section, Karolinska Institutet, Stockholm, Sweden

S Lindblad, Department of Medicine (Rheumatology), Karolinska Institutet

\section{REFERENCES}

1 Caine D, Cochrane B, Caine C, et al. An epidemiologic investigation of injuries affecting young competitive female gymnasts. Am J Sports Med 1989;17:811-20.

2 Garrick JG, Lewis SL. Career hazards for the dancers. Occup Med 2001;16:609-18.

3 Sands WA, Shultz BB, Newman AP. Women's gymnastics injuries. A 5-year study. Am J Sports Med 1993;21:271-6.

4 Bowling A. Injuries to dancers: prevalence, treatment, and perceptions of causes. BMJ 1989;298:734-6.

5 Kolt GS, Kirkby RJ. Epidemiology of injury in elite and subelite female gymnasts: a comparison of retrospective and prospective findings. $\mathrm{Br} J$ Sports Med 1999;33:312-18.

6 Bak K, Kalms SB, Olesen S, et al. Epidemiology of injuries in gymnastics. Scand J Med Sci Sports 1994;4:148-54.

7 Jorgensen U, Bojsen-Moller F. Shock absorbency of factors in the shoe/heel interaction - with special focus on role of the heel pad. Foot Ankle 1993;9:294-9.

8 Dixon M, Fricker P. Injuries to elite gymnasts over 10 yr. Med Sci Sports Exerc 1993;25:1322-29.

9 Eriksson K, Nemeth G, Eriksson E. Low back pain in elite cross-country skiers. A retrospective epidemiological study. Scand J Med Sci Sports 1996;6:31-5.

10 Kujala UM, Taimela S, Erkintalo $M$, et al. Low-back pain in adolescent athletes. Med Sci Sports Exerc 1996;28:165-70.

11 Swärd L, Hellstrom M, Jacobsson B, et al. Disc degeneration and associated abnormalities of the spine in elite gymnasts. A magnetic resonance imaging study. Spine $1991 ; 16: 437-43$.

12 Fridén C, Lindén Hirschberg A, Saartok T, et al. The influence of premenstrual symptoms on postural balance and kinesthesia during the menstrual cycle. Gynecol Endocrinol 2003;17:433-9.

13 Arokoski JPA, Kankaanpaa M, Valta T, et al. Back and hip extensor muscle function during therapeutic exercises. Arch Phys Med Rehabil 1999;80:842-50.

14 Lindner KJ, Caine DJ. Injury patterns of female competitive club gymnasts. Can J Sports Sci 1990;15:254-61. 